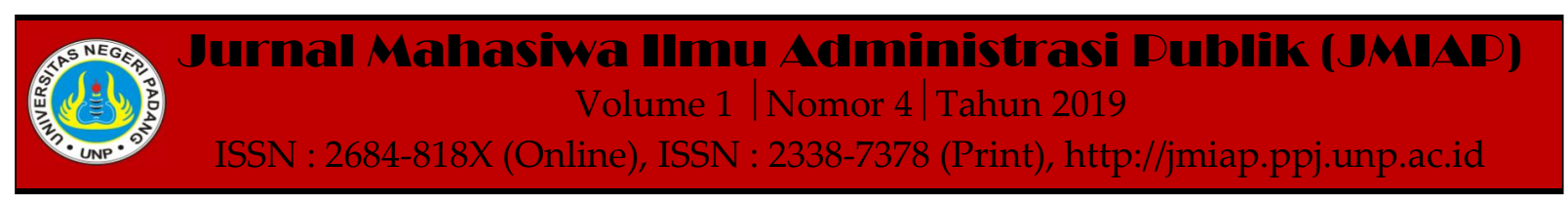

\title{
EFEKTIVITAS PELAKSANAAN FUNGSI KELOMPOK SIAGA BENCANA (KSB) KELURAHAN BUNGO PASANG DALAM MENINGKATKAN KESIAPSIAGAAN UNTUK MENGHADAPI BENCANA
}

\author{
Varisa Kenia Valery ${ }^{1(a)}$ dan Zikri Alhadi ${ }^{2(b)}$ \\ ${ }^{1}$ Jurusan Ilmu Administrasi Negara, Universitas Negeri Padang \\ ${ }^{2}$ Jurusan Ilmu Administrasi Negara, Universitas Negeri Padang \\ a)kenia.varisa@yahoo.co.id, ${ }^{b}$ ianunpzikri@yahoo.co.id
}

\begin{abstract}
Indonesia is one of the disaster-prone countries, where the city of Padang is included. Padang City's topography which has very varied characteristics makes Padang City vulnerable to disasters. Based on data from the Central Statistics Agency of the City of Padang the number of Subdistricts in the City of Padang is as much as 11 Sub-districts and the number of village in the City of Padang is as many as 104 village. From the Padang City RPB data, the level of disasters in the city of Padang varies. One of the villages that are prone to disasters is the Bungo Pasang Village, so to improve the preparedness of the Bungo Pasang Village in the form of a Disaster Preparedness Group (KSB) of the Bungo Pasang Village in 2011. However, currently the function of the Bungo Pasang Village KSB has not run optimally. , where there are still some obstacles faced by members of the KSB village Bungo Pasang. This study aims to determine the effectiveness of the implementation of the function of the Disaster Preparedness Group (KSB) of Bungo Pasang Village in improving preparedness to deal with disasters. This type of research is descriptive qualitative, where sources of data are taken through secondary data and primary data. Data collection techniques in the form of observation, interviews, and documentation.
\end{abstract}

Keywords : Disasters, implementation of Disaster Preparedness Group functions

Corresponding author. Email. kenia.varisa@yahoo.co.id,ianunpzikri@yahoo.co.id

How to cite this article. Valery, V. Kenia \& Alhadi. Z. (2019). Efektivitas Pelaksanaan Fungsi Kelompok Siaga Bencana (KSB) Kelurahan Bungo Pasang dalam Meningkatkan Kesiapsiagaan untuk Menghadapi Bencana. Jurnal Mahasiwa Ilmu Administrasi Publik (JMIAP) Jurusan Ilmu Administrasi Negara Fakultas Ilmu Sosial Universitas Negeri Padang, Volume 1 (4), Hal. 118-123.

http://jmiap.ppj.unp.ac.id

ISSN : 2684-818X (Online), ISSN : 2338-7378 (Print)

Copyright C2019. Published by Pusat Kajian-Pemberdayaan dan Pelayanan Masyarakat (PK-P2M) FIS UNP Padang 


\section{PENDAHULUAN}

Bencana merupakan kejadian yang terjadi baik oleh alam maupun oleh manusia itu sendiri. Bencana mengakibatkan korban penderitaan bagi manusia, kerugian harta benda, kerusakan lingkungan, sarana dan prasarana serta dapat menimbulkan gangguan terhadap tata kehidupan dan penghidupan masyarakat (Subdibyakto 2011). Ribuan bahkan ratusan ribu manusia menjadi korban bencana alam dengan berbagai jenisnya, seperti gempa bumi, stunami , tanah longsor, banjir, angin topan, gunung meletus, dan yang lainnya. Letak geologi dan tektonik indonesia yang membentuk jalur gempa dan jalur gunung api dengan ribuan pusat gempa dan ratusan gunung api menjadikan penyebab bencana alam berupa, gempa, tsunami dan gunung meletus (Harjono dan Priyono dalam Humaedi, dkk 2013:28).

Kota Padang menjadi salah satu daerah yang rawan bencana dimana secara garis besar Kota Padang dapat dibagi atas wialayah pantai dengan seluruh pinggiran pantai yang berhadapan dengan samudera hindia, wilayah dataran rendah yaitu wilayah yang sebagian besar sudah berkembang (termasuk kawasan pusat kota), dan wilayah dataran tinggi yaitu wilayah yang berada pada lereng bukit barisan. Topografi Kota Padang mempunyai karakterisitik yang sangat bervariasi tersebut menyebabkan Kota Padang rawan bahaya (Restra BPBD Kota Padang 2017-2019).

Berdasarkan hal tersebut maka dalam upaya untuk melakukan kesiapsiagaan bencana dari Pemerintah Daerah Kota Padang agar dapat mengurangi dampak yang ditimbulkan jika suatu waktu terjadi bencana maka diperlukanlah anggota masyarakat yang memiliki jiwa sosial relawan yang tinggi untuk membantu tugas Pemerintah tersebut. Sebagaimana pada undang-undang Nomor 24 tahun 2007 tentang Penanggulangan Bencana menetapkan bahwa Pemerintah dan
Pemerintah Daerah adalah penanggung jawab penyelenggaraan penanggulangan bencana. Namun pasal 27 undang-undang tersebut menegaskan bahwa setiap orang berkewajiban untuk melakukan kegiatan penanggulangan bencana.

Oleh Sebab itu untuk meningkatkan kesiapsiagaan dalam menghadapi bencana di Kota Padang di dibentuklah Kelompok Siaga Bencana (KSB) yang terdiri dari 11 KSB di Kecamatan Kota Padang dan 104 KSB di Kelurahan yang tersebar diberbagai wilayah di Kota Padang. KSB tersebut dibentuk oleh Badan Penanggulangan Bencana Dearah Kota Padang (BPBD Kota Padang) pada tahun 2011. Selanjutnya KSB yang berada di kelurahan merupakan perpanjangan tangan dari BPBD Kota Padang dalam menghadapi bencana yang kemungkinan terjadi di tengah-tengah masyarakat Kota Padang. Salah satu KSB yang ada di Kecamatan Koto Tangah adalah KSB Kelurahan Bungo Pasang yang berdiri pada tahun 2011 berdasarkan SK Lurah Bungo Pasang Kecamatan Koto Tangah No:SK.360.1/1/2018 tentang Pengesahan Keanggotaan Kelompok Siaga Bencana (KSB) Kelurahan Bungo Pasang Kecamatan Koto Tangah.

Peran KSB Kelurahan Bungo Pasang sendiri yaitu untuk mengatasi kesiapsiagaan bencana. Diantaranya yaitu yang paling utama karena Kelurahan Bungo Pasang berada dalam tingkat bahaya dengan kelas tinggi, selain itu mereka melakukan penyuluhan mengenai gempa dan tsunami, kemudian puting beliung, kebakaran, dan banjir. Namun pada kenyataannya KSB tersebut tidak selalu bagus tentu ada pasang surutnya, seperti yang kita ketahui bahwa KSB adalah relawan sosial tentu mereka memiliki pekerjaan utama disamping mereka menjadi relawan sosial.

Kepengurusan KSB Bungo Pasang yang lebih dari 25 anggota kebanyakan dari mereka memiliki latar belakang pengetahuan yang minim tentang kesiapsiagaan dalam mengatasi kebencaan 
di Kelurahan Bungo Pasang sendiri. Kemudian kendala lain yang di hadapi oleh KSB Kelurahan Bungo Pasang yaitu dari segi dana/anggaran, mereka tidak mendapatkan bantuan dana/anggaran dari BPBD atau Pemerintah Daerah untuk melakukan sebuah kegiatan. Dapat dijelaskan bahwa KSB Bungo Pasang melakukan kegiatan dengan memanfaatkan moment saja, jadi sifatnya itu insidentil, situasi, situasional. Selanjutnya KSB Kelurahan Bungo Pasang juga kurang mendapatkan perhatian dari BPBD maupaun dari Pemerintah Daerah. Disisi lain sosialisasi yang dilakukan oleh KSB Kelurahan Bungo Pasang di Kelurahan bungo Pasang hanya dilakukan ke daerahdaerah yang memang terdampak langsung terhadap ancaman resiko bencana seperti perumahan di pesisir pantai, rumah-rumah warga yang dirasa beresiko terkena bencana.

Berdasarkan permasalahan di atas dapat dikatakan bahwa pelaksanaan fungsi KSB Kelurahan Bungo Pasang belum berjalan maksimal sesuai dengan apa yang telah di tetapkan oleh SK KSB Kelurahan Bungo Pasang. Oleh sebab itu penulis tertarik untuk mengetahuinya dan menuangkannya dalam judul "Efektivitas pelaksanaan fungsi Kelompok Siaga Bencana (KSB) Kelurahan Bungo Pasang dalam meningkatkan kesiagsiagaan untuk menghadapi bencana.

\section{METODE PENELITIAN}

Penelitian ini merupakan penelitian kualitatif dengan menggunakan metode deskriptif. Dimana menurut Mukhtar (2013:10) menjelaskan bahwa penelitian kualitatif deskriptif yaitu penelitian yang dimaksud untuk medeskripsikan seluruh gejala atau keadaan yang ada pada saat proses penelitian berlangsung. Lokasi penelitian dilakukan Lokasi penelitian dilakukan di Kelurahan Bungo Pasang Kecamatan Koto Tangah J1. Simp. TabingLubuk Minturun . Data yang digunkana dalam penelitian ini merupakan data primer dan data sekunder. Pengumpulan data

dilakukan dengan $r$
observasi,wawancara, dan
dokumentasi. Teknik analisis dati
dilakukan dengan cara reduksi data,
penyajian data, dan verifikasi data
sedangkan teknik keabsahan data dilakukan
dengan trigulasi sumber.

HASIL DAN PEMBAHASAN

\begin{tabular}{llcc} 
Efektivitas & \multicolumn{2}{c}{ Pelaksanaan } & Fungsi \\
Kelompok & Siaga Bencana & (KSB) \\
Kelurahan Bungo Pasang & Dalam \\
Meningkatkan Kesiapsiagaan & untuk \\
Menghadapi Bencana &
\end{tabular}

Latar belakang terbentuknya organisasi Kelompok Siaga Bencana di Kota Padang ini didasari dan dilandasi terkait karakteristik potensi bencana dan berdasarkan demografi wilayah Kota Padang. Kelompok Siaga Bencana Kelurahan Bungo Pasang berdiri pada tanggal 11 november tahun 2011 yang di mediasi oleh NGO-NGO yang peduli terhadap kebencanaan, ada Mercy Koprs, ada Kogami, Ada Jemari Sakato dan yang lain.

Tugas dan fungsi Kelompok Siaga Bencana (KSB) yaitu yang pertama sebagai pemeditasi yang bersifat kerelawanan, kemasyarakatan, yang kedua berfungsi hanya sebagai bentuk panggilan kemanusiaan. Disisi lain sebagai Pencegahan dan kesiapsiagaan, Pada saat terjadi bencana, Setelah terjadi bencana dan Mendata dan melaporkan kejadian bencana yang ada didaerahnya.

Pelaksanaan fungsi Kelompok Siaga bencana di kelurahan Bungo Pasang dapat diketahui dari segi sosilasiasi yang dilakukan kepada masyarakat di Bungo Pasang berlum berjalan secara maksimal karena masih ada beberapa masyarakat khusunya RT dan RW yang tidak mengetahui tentang keberadaan KSB di Kelurahan Bungo Pasang. Selain itu sosialisasi yang dilakukan hanya kedaerahdaerah yang memang terdampak langsung terhadap ancaman bencana. Karena 
keterbatasan dana, kegiatan yang dilakukan kedaerah-daerah yang rawan tersebut tidak merata dilakukan.

Selain itu kegiatan sosialisasi yang dilakukan tidak rutin dijalankan dimana mereka hanya memanfaatkan momen saja, seperti ada kegiatan dari BPBD mensosialisasikan padang kota cerdas bencana. Di lain hal pendidikan dan pelatihan yang diterima oleh angota KSB Kelurahan Bungo Pasang masih kurang dimana mereka hanya mendapatkan pelatihan sekali setahun dari BPBD dan tidak semua anggota KSB Kelurahan Bungo Pasang mendapatkan pelatihan tersebut, karena hanya beberapa orang yang di ikut sertakan dalam pelatihan tersebut, otomatis untuk menunggu anggota lain mendapatkan pelatihan membutuhkan waktu yang cukup lama. Sedangkan kegiatan yang dilakukan oleh anggota KSB Kelurahan Bungo Pasang sendiri itu tidak ada.

Berdasarkan dari permasalahan yang telah di uraikan pada pendahuluan dapat diketahui bahwa kemampuan anggota KSB dalam melakukan sosialiasi hanya terfokus kepada masyarakat yang tempat tinggalnya berdekatan dengan pesisir pantai, karena pada dasarnya mereka memang memfokuskan kedaerah yang tingkat kerawanannya paling tinggi yaitu di daerah pesisir pantai. Namun ketika peneliti mensurvei kedaerah yaang telah ditargetkan tersbut, peneliti mendapati bahwa masih ada masyarakat di daerah pesisir pantai tersebut yang belum tahu dengan keberadaan KSB, otomatis mereka belum mendapatkan sosialiasi dari anggota KSB tersebut. Jadi kemampuan anggota KSB dalam melakukan koordinasi dengan masyarakat disana bisa dikatakan masih kurang, dimana tugas dan fungsi dari anggota KSB tersebut kurang berjalan dengan baik. Dapat dikatakan kemampuan anggota KSB Kelurahan Bungo Pasang dalam melakukan sosialiasi sesuai dengan tugas dan fungsinya belum maksimal karena masih kurangnya koordinasi yang dilakukan antara anggota KSB dengan masyarakat.

Dalam penelitian ini pengetahuan yang di terima oleh anggota KSB Kelurahan Bungo Pasang dalam hal pelatihan kebencanaan baik itu mitigasi kebencanaan belum cukup, karena mereka hanya mendapatkan pelatihan sekali setahun dari BPBD Kota dan beberapa kali pelatihan yang diberikan dari berbagai LSM yang ada di kota Padang seperti Kogami, Jemari dan LSM lainnya. Dapat dikatakan pelatihan yang diterima oleh anggota KSB ini masih kurang merata karena dalam setiap tahunnya hanya beberapa orang yang diikutkan dalam setiap kegiatan pelatihan, jadi mereka selalu bergiliran menerima pelatihan dari BPBD Kota Padang. Pelatihan yang diterima setiap tahunnya kurang lebih sama materinya yaitu tentang kebencanaan oleh karena itu dalam hal segi kebencanaan mereka sudah paham. Disisi lain pengetahuan yang di punya oleh anggota KSB yaitu tergantung bagaimana dia mendapatkan pelatihan, rata-rata pengetahuan yang dimiliki oleh anggota KSB sudah merata kecuali dengan seniorsenior yang memang sudah memiliki banyak pengalaman.

Sedangkan motivasi yang dimiliki oleh anggota KSB Kelurahan Bungo Pasang kurang lebih sama karena mereka bergabung dengan KSB tersebut di dasari atas dasar panggilan dari hati, atau dorongan ingin membantu sesama. Seperti yang diketahui bahwa Kota Padang adalah daerah yang rawan bencana kemudian Kelurahan Bungo Pasang adalah salah satu wilayah yang rawan terhadap bencana gempa dan tsunami karena berdekatan dengan pesisir pantai. Hal tersebutlah yang menjadikan mereka mau bergabung dengan KSB Kelurahan Bungo Pasang. Dimana rasa keterpanggilan untuk membantu sesama, mereka tidak memikirkan apa yang akan mereka peroleh atau apa yang mereka dapatkan dari ikut bergabung dengan KSB 
tapi mereka ingin memberikan apa yang bisa mereka berikan kepada masyarakat di Kelurahan Bungo Pasang. Apakah itu dari segi ilmu pengetahuan tentang kebencanaan atau dari segi informasi maupun dari bantuan tenaga sendiri.

\section{PENUTUP}

Berdasarkan hasil penelitian yang telah dilakukan, maka penulis dapat menarik kesimpulan bahwa efektivitas pelaksanaan fungsi Kelompok Siaga Bencana Kelurahan Bungo Pasang cukup efektif namun kurang optimal karena masih ada beberapa kendala yang dihadapi dalam pelakasaan tugas dan fungsinya. Efektivitas pelaksanaan fungsi Kelompok Siaga Bencana Kelurahan Bungo Pasang dalam meningkatkan kesiapsiagaan untuk menghadapi bencana dari segi kemampuan dapat dikatakan belum efektif karena tugas dan fungsi KSB Kelurahn Bungo Pasang belum terealiasi sampai ketingkan RT dan RW hal itu dapat dilihat dari segi koordinasi yang dilakukan oleh anggota KSB Kelurahan Bungo Pasang terhadap RT/RW masih belum maksimal, dimana RT/RW dikelurahan Bungo Pasang tidak mengetahaui dengan keberdaan KSB Bungo Pasang sendiri. Disisi lain kegiatan sosialisai yang dilakukan dapat dikatakan belum merata karena hanya terfokus pada wilayah yang terdmapak langsung terhadap ancaman bencana seperti pada wilayah di sepanjang pesisi pantai. Jadi dapat di simpulkan bahwa pelaksanaan tugas dan fungsi KSB Kelurahan Bungo Pasang belum berjalan sesuai dengan visi dan misinya.

Dari segi pengetahuan dapat dikatakan bahwa tingkat pengetahuan yang dimiliki oleh KSB Kelurahan Bungo Pasanag mengenai kebencaan rata-rata sudah merata atau sudah cukup baik, karena pada dasarnya mereka telah mendapatkan pelatihan tentang kebencanaan, baik itu dari BPBD Kota Padang maupun dari berbagai LSM yang telah melatih mereka seperti Kogami dan Jemari Sakato. Namun dalam tingkatan pelatihan yang mereka terima dari
BPBD Kota Pada setiap tahunnya masih kurang karena seperti yang telah dikatakan sebelumnya bahwa pelatihan yang diberikan itu masih kurang karena hanya dilakukan setahun sekali dan pelatihan tersebut dilakukan secara bergiliran dan itu tidak semuanya diikut sertakan dalam setiap pelatihannya hanya dipilih perwakilan dari setiap Kelurahan, Seperti dikelurahan Bungo Pasang hanya beberapa orang yang diikut sertakan sekitar 1 sampai 5 orang. Oleh sebab itu untuk menunggu giliran pendapatkan pelatiahn selanjutnya memakan waktu yang cukup lama. Jadi dapat disimpulkan dari segi tingkat pengetahuan sudah cukup baik namun belum maksimal karena masih kurangnya dilakukan pelatihan.

Dari segi motivasi yang dimiliki oleh anggota KSB Kelurahan Bungo Pasang dapat dikatakan bahwa mereka memiliki motivasi yang sama untuk ikut bergabung menjadi relawan di KSB Kelurahan Bungo Pasang yaitu rasa kepedulian dan ingin membantu sesama. Mereka memiliki tujuan menjadikan masyarakat dikelurahan Bungo Pasang menjadi masyarakat yang cerdas terhadap bencana. Berdasarkan hal tersebut peneliti menyarankan beberapa hal kepada Kelompok Siaga bencana (KSB) Kelurahan Bungo Pasang untuk meningkatkan pelaksanaan fungsi Kelompok Siaga Bencana Kelurahan Bungo Pasang sendiri dalam melakukan kesiapsiagaan untuk menghadapi bencana di Kelurahan Bungo Pasang diantaranya melakukan koordinasi antara KSB Kelurahan Bungo Pasang dengan RT/RW di Kelurahan Bungo Pasang di harapkan bisa lebih baik karena pada dasarnya yang menyampaikan langsung kemasyarakat disekitar wilayah tersebut tidak hanya KSB itu sendiri tetapi juga bisa dilakukan oleh RT/RWnya dimasing-masing perumahan itu melalui arahan dari KSB. Diharapkan untuk kedepannya sosialiasi akan merata dilakukan kesemua wilayah yang ada di Kelurahan Bungo Pasang tidak hanya terfokus kedaerah pesisir pantai. Untuk dari 
Varisa Kenia Valery, Zikri Alhadi I Efektivitas Pelaksanaan Fungsi Kelompok Siaga Bencana (KSB) Kelurahan Bungo Pasang dalam Meningkatkan Kesiapsiagaan untuk Menghadapi Bencana

segi pelatihan anggota KSB Kelurahan Bungo Pasang diharapkan juga membuat kegiatan pelatihan tidak hanya mengandalkan kegiatan pelatihan dari BPBD saja.

\section{DAFTAR KEPUSTAKAAN}

Mukhtar.2013. Metode Praktis Penelitian Deskriptif Kualitatif. Jakarta Selatan : Referensi ( GP Press Group).

Sudibyakto.2011. Manajemen di Indoesia Kemana?. Yogyakarta : Gadjah Mada University Press.

Humaedi,M Alie. Hisyam,M. Seftiani,Sari. Rembeth, j Viktor. 2013: Efektivitas
Peran Kepemimpinan Lokal dalam Upaya Pengurangan Resiko Bencana di Indonesia: Prosiding Geoteknologi LIPI.

Renstra BPBD Kota Padang 2017-2019.

Badan Pusat Statistik Kota Padang (Kota Padang Dalam Angka 2018).

Dokumen Rencana Kontijensi Bencana Tsunami Kota Padang Tahun Anggaran 2017.

SK Lurah Bungo Pasangg Kecamatan Koto Tangah.

Undang-undang Nomor 24 tahun 2007 tentang Penanggulangan Bencana. 